\title{
Medical teamwork and the evolution of safety science: a critical review
}

\author{
Christopher Neuhaus ${ }^{1,3}$ (1) Dag Erik Lutnæ2 ${ }^{2,3} \cdot$ Johan Bergström ${ }^{3}(0$
}

Received: 23 October 2018 / Accepted: 31 January 2019 / Published online: 12 February 2019

(c) The Author(s) 2019

\begin{abstract}
There is widespread consensus that teamwork constitutes one of the key requirements in today's multidisciplinary and highly complex system of delivering care. In recent years, increasing attention has been given to questions of how to define, teach, measure, and improve teamwork in healthcare. However, one cannot help but feel a certain disconnect between this ongoing trend in healthcare with an associated bias towards judgemental and normative language, and contemporary thinking in safety science that explores concepts from complexity thinking, such as emergence and resilience. The aim of this critical review is to contrast prevailing approaches to teamwork in healthcare with current concepts in safety science. After identifying relevant articles through multiple formal search methods, we found that, although current teamwork literature acknowledges a lack of comprehensive investigations linking team training in healthcare and patient outcomes, the predominant strategy to achieve safety remains a traditional, reactive approach that regulates behaviour and constrains performance variability. As this strategy is focussed on competencies, much of the responsibility for unwanted results is pushed towards the 'sharp end' by the quality agenda, emphasizing personal and professional competence while obscuring systemic issues. Teamwork, while indispensable in the highly subspecialized reality of healthcare, is oftentimes reduced to an aggregated set of individual behaviours. It appears that in the current state of entangled quality and safety agendas, medicine has settled for a reductionist and moral approach towards teamwork to manage the associated complexities, thereby accepting a simplistic but intellectually impoverished and ethically questionable understanding of the concept.
\end{abstract}

Keywords Teamwork $\cdot$ Patient safety $\cdot$ Safety science

\section{Introduction}

Many of the early safety efforts in medicine were modelled after experiences from the aviation industry, including the implementation of simulation to educate practitioners about human factors. These training programs, so-called 'crewresource-management' (CRM) programs, usually address a number of cognitive and social competencies that are deemed relevant or essential for safety, sometimes dubbed

Christopher Neuhaus and Dag Erik Lutnæs equally contributed to the manuscript.

Christopher Neuhaus

c.neuhaus@uni-heidelberg.de

1 Department of Anesthesiology, University Hospital Heidelberg, Im Neuenheimer Feld 110, 69120 Heidelberg, Germany

2 SAFER, Stavanger, Norway

3 Division of Risk Management and Societal Safety, Lund University, Lund, Sweden 'non-technical skills'. In recent years, increasing attention has been given to the idea of teamwork: how to define, teach, measure, and improve it. There is widespread consensus that teamwork constitutes one of the key requirements in today's multidisciplinary and highly complex system of delivering care. However, one cannot help but feel a certain disconnect between this ongoing trend in healthcare, with a heavy bias towards judgemental and normative language, and contemporary thinking in safety science that explores concepts from complexity thinking, such as emergence and resilience. The aim of this review is to contrast prevailing approaches to teamwork in healthcare with current concepts in safety science while including a critical discourse to bridge the gap between different research traditions and disciplines. The remainder of this paper is structured as follows: Sect. 2 provides a description of traditional and more recent approaches to safety. This description is not meant to provide an exhaustive review of the literature, but rather to illustrate recent advances and the diversity found in the domain. Section 3 provides a review of current concepts 
on teamwork in healthcare and positions these within the frameworks provided by safety science research. The critical aspects of the article are mainly found in Sect. 4, where we reveal and discuss inconsistencies in the way that healthcare has attempted to implement safety science research, and what body of knowledge has so far largely been ignored. Subsequently, we try to contrast, and hope to merge, two realms of teamwork research: one as viewed through a normative lens with one including current concepts from safety science.

\subsection{Methods}

In line with previously published methodology for narrative and critical reviews (Baumeister and Leary 1997; Paré et al. 2015), we identified articles through multiple formal search methods, including the electronic searching of databases using free-text, index terms, and author names. Electronic searches of the databases Scopus, Google Scholar, and PubMed were conducted. Free-text searches included combinations of the terms "healthcare", "interdisciplinary", "multidisciplinary", "team", "teamwork", and "team training". Snowballing and identification of studies through personal knowledge were also used. In addition, serendipitous discovery yielded relevant articles.

\section{Theoretical foundations of patient safety}

\subsection{Traditional approaches}

If one had to choose the predominant theoretical lineage of widespread safety efforts in healthcare, it would most likely lead to a predominantly Newtonian worldview: to design a safe system, much emphasis is placed on a good blueprint, proper rules, procedures and compliance therewith, all to establish barriers for error detection and prevention. Safety, in this context, is defined as "freedom from accidental injury" by institutions like the US Institute of Medicine or the US Agency for Healthcare Research and Quality (Kohn et al. 2000, p. 18). This concept, which has been described as 'Safety-I' by Erik Hollnagel (2014, p. 50), is representative of an often encountered, and rarely questioned, one-sizefits-all approach that is prevalent in a domain increasingly susceptible to quick fixes. The idea promotes a linear, binary understanding of work that can either succeed or fail and focuses on transitions between normal and abnormal system states. "According to the logic of Safety-I, safety and efficiency can be achieved if this transition can be blocked. This unavoidably leads to an emphasis on compliance in the way work is carried out" (Hollnagel et al. 2013, p. 7). It also presupposes that the underlying causes for successes and failures are different. Consequently, safety can be achieved by regulating and constraining performance variability, through means of, e.g., training, standard operating procedures, rules, or checklists, for which there is ample evidence in healthcare (Allard et al. 2011; Arriaga et al. 2013; Haynes et al. 2009; Neuhaus et al. 2017; Ornato and Peberdy 2014; Russ et al. 2013; Rydenfalt et al. 2013).

On an individual level, much emphasis is placed on proper behaviour, to the extent that it can be categorized, rated, and trained:

[Non-technical-skills] can be defined as "the cognitive, social and personal resource skills that complement technical skills, and contribute to safe and efficient task performance" [...] Poor NTS can increase the chance of error, which in turn can increase the chance of an adverse event. Good NTS (e.g., high vigilance, clear communication and team co-ordination) can reduce the likelihood of error and consequently of accidents. Analysis of incidents, as well as studies of behaviour during routine work (task analysis), can reveal which workplace behaviours positively or negatively influence job performance and adverse events. (Flin and Maran 2015, emphasis added)

Still, heavily based on linear thinking (Dekker 2014, pp. 27-43) and clear-cut cause-effect relationships, healthcare has done little so far to embrace alternative approaches to safety (Levitt 2014).

\subsection{Safety as emergent property}

The overarching idea of more recent approaches to safety that has so far been inadequately addressed in healthcare is as follows: how can we harness the capacity of individuals to successfully collaborate and produce safety as an emergent property of normal work, given the multi-professional and dynamic nature of modern medicine? Many approaches to this question have been described, mostly using examples from other domains: high-reliability theorists (HRT) have made various cases for "large, formal organizations that perform complex, inherently hazardous, and highly technical tasks under conditions of tight coupling and severe time pressure" (Rochlin et al. 1987). What follows is a theory that is much more reliant on a social construction of safety, emphasizing implicit norms, myths, and on-the-job training than merely devising SOPs and guidelines (Rochlin 1999). All these properties invite a transfer to healthcare, of which we have seen little so far (Roberts et al. 2005). Similarities, however, are abundant. Rochlin et al. (1987) describe the culture among US Navy officers as follows: "The potential risk of attempting to operate at present levels under increasing budgetary constraints arises, because the Navy is a "cando" organization, visibly reluctant to say "we're not ready" until the situation is far into the red zone." The same is found 
in healthcare, although underlying motivations might vary: one could argue that both in the military, and in healthcare, there is a certain ethos to be found that extends beyond a mere financial interest, simply because economic profitability is not (or should not be) the organization's top priority.

Beyond HRT, many more ideas exist: Schulman (2004) nuances models of reliability in healthcare. One way to create reliability, Schulman argues, is by having well-formed rules applied to predictable settings. Reliability can then be achieved by mostly controlling or thoroughly knowing the "input". The other form of reliability described by Schulman (2004) is having such robust organizational mechanisms that it can cope with complexity or manage variability. This approach is consistent with ideas from resilience engineering (Hollnagel and Woods 2006; Woods 2015), although some authors are reluctant to use the term. Vincent and Amalberti (2016) choose to not mention resilience; however, they do emphasize the need for capacities to adapt and recover without using the exact word; which makes their approach congruent with the resilience engineering thinking. In short, complexity scholars add some distinctive vocabulary to supplement their theoretical approach: ideas like discretional or operational space add their own dimension to understanding safety in healthcare. According to Rasmussen (1997):

Human behaviour in any work system is shaped by objectives and constraints which must be respected by the actors for work performance to be successful. Aiming at such productive targets, however, many degrees of freedom are left open which will have to be closed by the individual actor by an adaptive search guided by process criteria such as work load, cost effectiveness, risk of failure, joy of exploration, etc. (Rasmussen 1997)

This applies to both the individual and the organizational level. Although an organization will try to shape individual behaviour by defining this operational space (e.g., through the use of SOPs or guidelines), Rasmussen et al. (1990) note that " $[\ldots]$ the structuring of work processes $[\ldots]$ by an individual will be a self-organizing, evolutionary process, simply because an optimizing search is the only way in which the large number of degrees of freedom in a complex situation can be resolved". This becomes increasingly problematic in the dynamic environment of everyday work:

[A]ll work situations leave many degrees of freedom to the actors for choice of means and time for action even when the objectives of work are fulfilled and a task instruction or standard operating procedure in terms of sequence of acts cannot be used as a reference of judging behaviour [...] In consequence, rules, laws, and instructions practically speaking are never followed to the letter. (Rasmussen 1997)
Constructing a 'discretional space' out of degrees of freedom paves, the way for understanding the aforementioned emergent phenomena: drawing on complexity theory and systems thinking, they are the result of relationships and interactions of constituent components performing (mostly) normal work. No single component can mirror the behaviour of the system as a whole (Dekker et al. 2011; Rasmussen 1997), and system behaviour cannot be predicted on the basis of the individual components that comprise it (Dekker et al. 2011, pp. 127-168). Socio-technical systems are becoming increasingly intractable (Hollnagel et al. 2011, p. 286), resulting in the inability of traditional safety management ideas to serve as the only viable approach, as they presume that the systems' behaviour is understood and predictable. This establishes the need to study and understand everyday work with a focus on successful outcomes instead of failures; a fundamental shift in thinking that has been called 'Safety-II' by Hollnagel et al. (2013, pp. 3-18):

Safety-II explicitly assumes that systems work because people are able to adjust what they do to match the conditions of work. [...] The result of that is performance variability, not in the negative sense where variability is seen as a deviation from some norm or standard, but in the positive sense that variability represents the adjustments that are the basis for safety and productivity. (Hollnagel et al. 2013, p. 12)

Safety-II acknowledges that our understanding of current socio-technical systems is incomplete and unable to account for the dynamics, irregularities and goal conflicts encountered in the messy everyday realities of organizational life. It is important to note, however, that Safety-II should not be seen as a replacement strategy of Safety-I, but rather a way of thinking about human performance that complements and enlarges traditional thinking to better address future needs.

\subsection{Finishing the design}

Complexity thinkers have advocated for a new understanding of the role of humans in these complex systems: they represent the crucial, and maybe most vulnerable, link between theory and practice, as they are the ones that have to "finish the design" (Dekker 2014, p. 100). No workplace design, in the form of procedures, SOPs or guidelines, can include all eventualities in a complex adaptive system (CAS) such as healthcare. Therefore, the individual adaptive capacity of the professional is needed to make things work (Hollnagel 2014, pp. 167-169).

As agents within systems interact, jostle with, and influence each other, $[\ldots]$ they exhibit and produce emergent behaviours. Agents (clinical staff, ancillary and support staff, and managers) actively participate 
in what Strauss et al. (1963) and Strauss (1978) called 'the negotiated order' - a term coined to emphasize the way people parley, confer and make trade-offs in meeting their individual and group objectives. These politically and culturally informed exchanges go a long way towards describing the organizational dynamics underpinning the process of providing care. (Braithwaite et al. 2013, p. 66)

Therefore, instead of a problem to control, humans in these systems become the resource to harness. Radically different from the traditional view on safety as described above, this controversy has been at the core of much debate in safety science over the last decades (Dekker 2011, 2014; Woods et al. 2010). This should be kept in mind when exploring current approaches to teamwork in healthcare.

\section{Understanding teamwork in healthcare}

\subsection{General considerations}

Together with increasing awareness for patient safety in general, the seminal Institute of Medicine report "To Err Is Human" (Kohn et al. 2000) was one of the first publications that highlighted the importance of team performance in healthcare and inspired subsequent research. One can only speculate about reasons for how readily the connection between patient safety and teamwork was drawn, and we will try to explore some of those aspects in the following sections. Current teamwork literature acknowledges a lack of comprehensive investigations linking team training in healthcare and patient outcomes (Weaver et al. 2010). However, focussing on outcome of work rather than its process demonstrates how entangled the quality and safety agendas have become in medicine. "Because of the conflation of safety with quality, safety is seen as an attribute of quality $[. .$.$] rather than an emergent, thus dynamic, property$ of everyday work to manage trade-offs without doing harm" (Hollnagel et al. 2013, pp. 50-51). This has important implications: the predominant strategy to achieve safety remains a traditional, reactive approach that regulates behaviour and constrains performance variability. We will show below that, as this strategy is focussed on competencies, much of the responsibility for unwanted results is pushed towards the 'sharp end' by the quality agenda, emphasizing personal and professional competence while obscuring systemic issues. Teamwork, while indispensable in the highly subspecialized reality of healthcare, is thereby oftentimes reduced to an aggregated set of individual behaviours.

\subsection{Team: a definition}

One of the predominant definitions of a team is "a set of two or more individuals interacting adaptively, interdependently and dynamically towards a common and valued goal" (Salas et al. 2000). Manser (2009) further highlights aspects that are especially relevant for healthcare, among them task-specific competencies and specialized work roles while using shared resources. Due to the domain's dynamic nature, medical teams have changing membership, are assembled "ad hoc", and incorporate heavily subspecialized members while integrating different professional cultures (Manser 2009; Østergaard et al. 2011). The fact that healthcare is far from being a homogenous domain might be more crucial for our understanding of teamwork than what has been previously acknowledged: it has been described as "20 different industries under one banner" (Vincent and Amalberti 2016, p. 7), covering properties from 'high risk' like emergency surgery, through 'high-reliability' like routine daily work on wards to 'ultra-safe' such as transfusion logistics. Both the patient and the healthcare professional constantly, but not always consciously, transition between different categories (Vincent and Amalberti 2016) ${ }^{1}$. Subsequently, team literature often stresses the need for co-ordination, communication, and leadership (Salas et al. 2000).

\subsection{Frameworks}

Attempts to study and describe team processes started in the 1950s and have exponentially grown in recent years (Paris et al. 2000). Over time, the sheer number of the proposed aspects of teamwork has grown to be both incomprehensibly large and riddled with inconsistencies and confusion (Cannon-Bowers et al. 1995). A review by Burke et al. (1993) found over 130 different labels to describe aspects of teamwork. While frameworks encompassing these various labels differ greatly in granularity and context, some core concepts, such as the input-process-output (IPO) framework (McGrath 1964) and reference to different types of teams, can be identified (Salas et al. 2008; Sundstrom 1999). It is important to remember that historically, the main stimulus for team

\footnotetext{
${ }^{1}$ For example, a trauma patient in the ER, with life-threatening injuries, is in the domain of 'high-risk' because of his condition, thereby establishing the same category for the trauma-team. However, the procedure for inserting a bladder catheter to monitor his urine output will be within the 'high-reliability' domain while the type $\mathrm{O}$ negative blood that is given has an 'ultra-safe' property. Moreover, the same personnel that treated this trauma patient may treat an elective patient next, a situation where the 'high-risk' categorization would be unacceptable. However, while this might almost fall into the category of 'ultra-safe' (Vincent and Amalberti 2016, p. 29), there is no guarantee that the situation will stay that way due to the dynamic nature of healthcare.
} 
research has been tied to what is commonly understood as 'team failures', particularly associated with high-visibility accidents (Ilgen 1999); a development that is congruent with predominant understanding of safety at the time, or what we have introduced above as the 'philosophy' of Safety-I (Hollnagel 2014, p. 50). This also resulted in increasingly blurred lines between mere descriptive efforts and more normative guidance for improved teamwork (Paris et al. 2000).

Cannon-Bowers et al. (1995) reviewed and synthesized the field to describe eight generalizable core dimensions of teamwork: adaptability, shared situational awareness, performance monitoring and feedback, leadership/team management, interpersonal relations, co-ordination, communication and decision-making (for further detail, see Table 1).

The same group of researchers, arguably the most prominent and influential in the field, subsequently began to " $[\ldots]$ develop a set of prescriptive guidelines that can be utilized for training and selection" (Salas et al. 2000, for further information, see Table 1). These categories were further condensed for a specific healthcare context in a review by Manser (2009, see Table 2).

\subsection{Same, same but different: cultural influences}

Klampfer et al. (2001) stress the need to consider cultural differences in teamwork research, pertaining to both national but also organizational and departmental cultures. Salas et al. (2008) address the salient need to understand the role of culture in team performance in light of progressing globalization: "To date, the bulk of team performance research involves US or Western populations. [This] raises the possibility that the extant models are insufficient for teams with a heterogeneous cultural composition." (p. 545). In fact, one could describe a certain cultural hegemony in medical teamwork research. While we could identify some management literature concerned with the topic, insight into the influence of national culture on teamwork in healthcare remains scarce. In addition to questioning the validity and applicability of a certain framework in a specific cultural context, the fundamental assumptions underlying that framework have to be re-examined before considering its implementation.

\subsection{Training teamwork}

Although healthcare is more and more coming to the realization that merely adopting training concepts that have proven successful in other domains does little to improve patient safety (Neuhaus et al. 2016; Vincent and Amalberti 2016, p. 7), there is widespread consensus that teamwork constitutes one of the key requirements in today's multidisciplinary and highly complex system of delivering care.

Many of the early safety efforts in medicine were modelled after experiences from the aviation industry, including the implementation of simulation to educate practitioners about human factors (Gaba 1989; Howard et al. 1992). These training programs usually address a number of cognitive and social competencies that are deemed relevant or essential for safety, sometimes dubbed 'non-technical skills' (NTS, Flin and Maran 2015; Flin et al. 2009). Initially conceived as "Cockpit Resource Management" (CRM) programs in the aviation industry (Helmreich et al. 1999), the evolution of these concepts and inclusion of a larger audience has led to various adaptations such as 'Crew Resource Management', "Anaesthesia Crisis Resource Management" (Howard et al. 1992) or "Emergency Medicine Crisis Resource Management" (Reznek et al. 2003). Weaver et al. (2010) could demonstrate that most team training programs in healthcare are modelled on CRM principles (see Table 3) while incorporating both high- and low-fidelity simulation to enhance learning (Lorello et al. 2014). One cannot help but notice a certain overlap between the terms NTS and CRM, to the point, where the original authors talk about "NTS/CRM training" (Flin et al. 2008). The NTS framework, while targeting a variety of occupations, has also been adapted for special healthcare applications such as Anaesthetists' Non-Technical Skills (ANTS; Flin et al. 2010, for further information, see Table 3), and Non-Technical Skills for Surgeons (NOTSS; Yule et al. 2006).

Over the last 25 years, CRM training in healthcare has raised awareness about the influence of human factors in medicine, and generally contributed to positive attitudes towards patient safety and CRM training (Morey et al. 2002; Østergaard et al. 2011). Quite imprecisely, 'CRM' has been internalized by practitioners to the point where it has become an eponym for many different kinds of human factor-related interventions in healthcare.

In a critical review, Salas, Wilson, Burke, and Wightman (2006) point out a lack of standardisation in CRM training:

In addition, the various names associated with CRM training $[\ldots]$ indicate the lack of consensus among domains as to how to label or define CRM. Furthermore, there is no standardization as to what competencies (i.e., knowledge, skills, and attitudes) are to be trained. (Salas et al. 2006)

Although wholeheartedly embraced by the medical community, a review on the impact of CRM training by Salas et al. (2006) could only find partial support for its effectiveness: there seems to be a limited influence on teamwork attitudes as well as demonstrated behaviours (Morey et al. 2002), as well as a certain "ceiling effect" related to trainees' experience (Howard et al. 1992). In addition, there is little to no standard for the qualification of CRM instructors in healthcare. In a review of 48 studies on team training in healthcare, Weaver et al. (2010) report that "[n]one of the studies provided meaningful details regarding how 
Table 1 Integrated teamwork skill dimensions (Cannon-Bowers et al. 1995, as cited by; Salas et al. 2000)

\begin{tabular}{|c|c|c|}
\hline Skill dimension & Definition & Subskills/alternate labels \\
\hline Adaptability & $\begin{array}{l}\text { Process by which a team is able to use information } \\
\text { gathered from the task environment to adjust strat- } \\
\text { egies through the use of compensatory behaviour } \\
\text { and reallocation of intra-team resources }\end{array}$ & $\begin{array}{l}\text { Flexibility } \\
\text { Capacity for closure } \\
\text { Development of innovation } \\
\text { Mutual adjustment } \\
\text { Compensatory behaviour } \\
\text { Backing-up behaviour } \\
\text { Provide/ask for assistance } \\
\text { Fail stop } \\
\text { Dynamic reallocation of functions }\end{array}$ \\
\hline Shared situational awareness & $\begin{array}{l}\text { Process by which team members develop compat- } \\
\text { ible models of the team's internal and external } \\
\text { environment; includes skill in arriving at a com- } \\
\text { mon understanding of the situation and applying } \\
\text { appropriate task strategies }\end{array}$ & $\begin{array}{l}\text { Situational awareness } \\
\text { Orientation } \\
\text { Team awareness } \\
\text { Development of integrated model of environment } \\
\text { Development of system awareness } \\
\text { Shared problem model development }\end{array}$ \\
\hline Performance monitoring and feedback & $\begin{array}{l}\text { Ability of team members to give, seek and receive } \\
\text { task clarifying feedback; includes the ability } \\
\text { to accurately monitor the performance of team } \\
\text { mates, provide constructive feedback regarding } \\
\text { errors and offer advice for improving performance }\end{array}$ & $\begin{array}{l}\text { Intra-member feedback } \\
\text { Performance feedback } \\
\text { Planning review } \\
\text { Feedback/reinforcement } \\
\text { Acceptance of/giving suggestions, criticism } \\
\text { Mutual performance monitoring } \\
\text { Monitoring and cross checking } \\
\text { Systems monitoring Performance monitor- } \\
\text { ing Error id/correction } \\
\text { Intra-team monitoring } \\
\text { Strategy development } \\
\text { Procedure maintenance }\end{array}$ \\
\hline Leadership/team management & $\begin{array}{l}\text { Ability to direct and co-ordinate the activities of } \\
\text { other team members, assess team performance, } \\
\text { assign tasks, motivate team members, plan and } \\
\text { organize and establish a positive atmosphere }\end{array}$ & $\begin{array}{l}\text { Task structuring } \\
\text { Delegation and assignment } \\
\text { Task assignment } \\
\text { Resource distribution } \\
\text { Resource management } \\
\text { Performance direction } \\
\text { Establishment of priorities Mission analysis } \\
\text { Motivation of others } \\
\text { Leadership control } \\
\text { Goal setting } \\
\text { Drive to completion } \\
\text { Goal orientation }\end{array}$ \\
\hline Interpersonal relations & $\begin{array}{l}\text { Ability to optimize the quality of team members' } \\
\text { interactions through resolution of dissent, utiliza- } \\
\text { tion of co-operative behaviours, or use of motiva- } \\
\text { tional reinforcing statements }\end{array}$ & $\begin{array}{l}\text { Conflict resolution } \\
\text { Co-operation (interpersonal) } \\
\text { Assertiveness } \\
\text { Morale building (beh. reinforcemt.) } \\
\text { Boundary spanning }\end{array}$ \\
\hline Co-ordination & $\begin{array}{l}\text { Process by which team resources, activities and } \\
\text { responses are organized to ensure that tasks are } \\
\text { integrated, synchronized and completed within } \\
\text { established temporal constraints }\end{array}$ & $\begin{array}{l}\text { Task organization } \\
\text { Co-ordination of task sequence } \\
\text { Integration } \\
\text { Task interaction } \\
\text { Technical co-ordination } \\
\text { Response co-ordination } \\
\text { Timing and activity pacing }\end{array}$ \\
\hline Communication & $\begin{array}{l}\text { Process by which information is clearly and accu- } \\
\text { rately exchanged between two or more team mem- } \\
\text { bers in the prescribed manner and with proper } \\
\text { terminology; the ability to clarify or acknowledge } \\
\text { the receipt of information }\end{array}$ & $\begin{array}{l}\text { Information exchange } \\
\text { Closed-loop communication Information sharing } \\
\text { Procedural talk Volunteering/requesting info } \\
\text { Consulting with others } \\
\text { Effective influence } \\
\text { Open exchange of relevant info } \\
\text { Evaluative interchange }\end{array}$ \\
\hline
\end{tabular}


Table 1 (continued)

\begin{tabular}{|c|c|c|}
\hline Skill dimension & Definition & Subskills/alternate labels \\
\hline Decision making & $\begin{array}{l}\text { Ability to gather and integrate information, use } \\
\text { sound judgement, identify alternatives, select the } \\
\text { best solution, and evaluate the consequences (in } \\
\text { team context, emphasizes skill in pooling infor- } \\
\text { mation and resources in support of a response } \\
\text { choice) }\end{array}$ & $\begin{array}{l}\text { Problem assessment } \\
\text { Problem solving } \\
\text { Emergence of solutions } \\
\text { Probabilistic structure } \\
\text { Hypothesis formulation } \\
\text { Information processing } \\
\text { Information evaluation } \\
\text { Planning development } \\
\text { Use of information } \\
\text { Metacognitive behaviour } \\
\text { Implementation (jurisdiction) }\end{array}$ \\
\hline
\end{tabular}

Table 2 Overview of aspects of teamwork relevant to the quality and safety of patient care in dynamical domains of healthcare (Manser 2009)

\begin{tabular}{ll}
\hline Aspects of teamwork & Examples of safety-relevant characteristics \\
\hline Quality of collaboration & Mutual respect \\
& Trust \\
Shared mental models & Strength of shared goals \\
& Shared perception of a situation \\
& Shared understanding of team structure, team task, team roles, etc \\
Co-ordination & Adaptive co-ordination (e.g., dynamic task allocation when new members join the team; shift \\
& between explicit and implicit forms of co-ordination; increased information exchange and plan- \\
& ning in critical situations) \\
Communication & Openness of communication \\
& Quality of communication (e.g., shared frames of reference) \\
& Specific communication practices (e.g., team briefing) \\
Leadership & Leadership style (value contributions from staff, encourage participation in decision-making, etc.) \\
& Adaptive leadership behaviour (e.g., increased explicit leadership behaviour in critical situations) \\
\hline
\end{tabular}

trainers themselves were prepared to train teamwork skills or explicated the skills sets important for trainer effectiveness." Moreover, the evidence for so-called 'train the trainer' activities is very limited. The literature suggests that with various training concepts readily available, individual needs are only rarely established for training development and implementation, thereby supporting a 'one-size-fits-all' approach to team training (Weaver et al. 2010).

\subsection{Measuring teamwork}

In line with a general trend towards quantitative research in healthcare (Vincent 2009), a variety of frameworks exist to measure various aspects of teamwork. In an effort "to consolidate the statistical evidence for the effects of team processes on clinical performance", Schmutz and Manser (2013) identified 28 studies that generally indicated that team processes significantly influence clinical performance. They, nevertheless, note the lack of a common conceptual framework and vague definitions. While models exist that reflect the complexity of teamwork, they are usually too complex for isolated research questions in healthcare. The two observation systems most often used are the observation method of Manser et al. (2008) and the behavioural marker system NOTECHS (Catchpole et al. 2007, see Table 4). While the former is descriptive and records actions without evaluation, in the latter, target behaviours are rated on a numeric scale for a defined episode. "This evaluative component may artificially increase the relationship with performance ratings, while descriptive observation systems provide more objective data on the team process." (Schmutz and Manser 2013). Lemieux-Charles and McGuire (2006) reach a similar conclusion by reinforcing the need for "[...] rigorous conceptualization of team dimensions, processes and traits, and outcomes" in teamwork effectiveness research after identifying corresponding gaps in the literature.

In a critical review, Jepsen et al. (2015) examined 23 different frameworks for assessing non-technical skills in healthcare. Overarching categories included cognitive and social skills, subdivided into cognitive categories such as: 'situational awareness', 'decision making' and 'empathy and sensitivity' and social categories such as: 'Communication', 'teamwork', (shared) 'leadership', 'task management', 'organization' and 'working under pressure'. The same categories in different instruments were found to encompass different concepts and also overlap with 
Table 3 Illustrates the relationship between the elements in the anaesthesia non-technical skills (ANTS) system and the crisis resource management (CRM) system (Østergaard et al. 2011)

\begin{tabular}{|c|c|}
\hline ANTS & CRM \\
\hline \multicolumn{2}{|l|}{ Cognitive and mental skills } \\
\hline Planning and preparing & $\begin{array}{l}\text { Anticipate and plan } \\
\text { Know your environment }\end{array}$ \\
\hline Prioritising & $\begin{array}{l}\text { Exercise leadership } \\
\text { Set priorities dynamically }\end{array}$ \\
\hline Provide and maintain standards & Use cognitive aids \\
\hline Identify and use resources & $\begin{array}{l}\text { Distribute workload } \\
\text { Mobilise all available resources }\end{array}$ \\
\hline Gathering information & Use all available resources \\
\hline Recognizing and understanding & Allocate attention \\
\hline Anticipating & Anticipate and plan \\
\hline \multicolumn{2}{|l|}{ Identifying options } \\
\hline $\begin{array}{l}\text { Balancing risks and selecting } \\
\text { options }\end{array}$ & Prevent and manage fixation errors \\
\hline Re-evaluating & Re-evaluate repeatedly \\
\hline \multicolumn{2}{|l|}{ Social and interpersonal skills } \\
\hline $\begin{array}{l}\text { Coordinating activities with } \\
\text { team }\end{array}$ & $\begin{array}{l}\text { Communicate effectively } \\
\text { Teamwork }\end{array}$ \\
\hline Exchanging information & Communicate effectively \\
\hline $\begin{array}{l}\text { Using authority and assertive- } \\
\text { ness }\end{array}$ & $\begin{array}{l}\text { Exercise leadership and follower- } \\
\text { ship }\end{array}$ \\
\hline \multicolumn{2}{|l|}{ Assessing capabilities } \\
\hline Supporting others & Exercise followership \\
\hline
\end{tabular}

different categories in other instruments. However, this overall lack of concept validity is not unique to healthcare, but has been described for teamwork assessment in other domains (Weber and Dekker 2017).

Further adding to the complexity and difficulty of standardised measurements are that team compositions constantly change, the lack of rater training, and difficulty defining specific context where the instrument should be used. There is no "gold standard" for ratings of NTS, and it is acknowledged that this is difficult to achieve, especially in light of constantly changing criteria for the development of behavioural markers as healthcare organizations evolve (Jepsen et al. 2015). Considering these aspects, it seems wise to be sensitive to consequences of implementing measurement tools:

One challenge that underlies each assessment instrument is that its values might be taken for the real thing. It is important to note that each of the instruments contains constructs that aim to describe complex socio-technical systems. They do so by reducing complexity, by levelling fine-grained differences and by forcing raters into perceiving and thinking in a standardised way, what could be perceived as the downside of bringing the topics into the discussion by using standardised terms (Jepsen et al. 2015)

In addition, if a specific framework is used throughout a professional education or in post-graduate evaluation, those being rated may adapt the framework as the "only" aspects of NTS that are important. Other crucial aspects of real work in the complex adaptive system, not described in the preferred framework, will be lost or ignored, because the healthcare professionals have been nurtured, evaluated, and given feedback solely on aspects included in the specific framework. Even if one argues that it is 'just' a measurement tool, not intended to reflect the whole, complex reality, over time, it is likely to make healthcare professionals focus on the specific aspects they are being evaluated on.

You get an idea and you begin to look for it and you suddenly see it everywhere, and that is when you have to be a bit cautious because it shouldn't take over. Because it is just an idea, it is not a psychological mechanism, it's just a convenient way of describing things, and any convenient way of describing things will capture something that's essential and throw away things that also potentially could be essential, that's why you have to be very careful all the time about how you describe things. (Erik Hollnagel in Conklin 2018)

As Jepsen et al. (2015) caution, real human and professional capabilities could ultimately be replaced by those from the assessment instrument. In summary, if categories of a framework constitute the 'dominant' truth of a professional's narrative, it might render them blind to other, equally important, aspects.

\section{Normative concerns, scientific disconnect and blind spots}

\subsection{Bias in teamwork research}

Ilgen (1999) first voiced concerns toward what he called a "normative bias" in teamwork research to address the trend of researchers more focussed on increasing than simply understanding team performance:

Normative models, in contrast to descriptive ones, usually start with a purpose to develop ways to improve teams so that behavior in them will meet some objective. [...]. Once the model is constructed, the task of evaluating its normative value follows. (Ilgen 1999)

Taken one step further, and quite contrary to the humanistic title of the IOM report, there is an abundance of teamwork literature that reads both judgemental and biased with hindsight while pointing at the individual operator, 


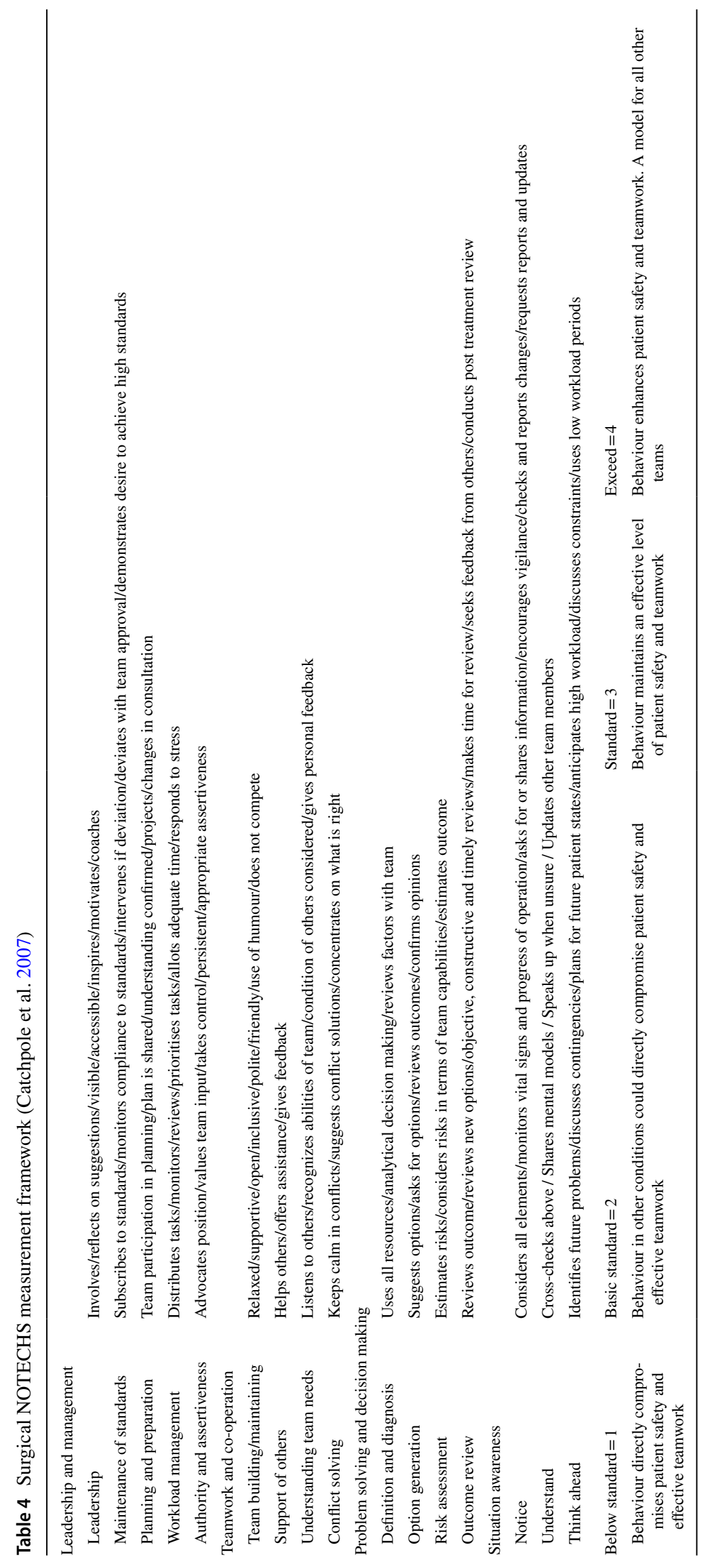


or 'sharp end' of a system. Talk about 'failures' or 'breakdowns', be it of teamwork or communication, and attributes such as 'good', 'bad' and 'poor' in combination with any 'non-technical skill' is plentiful (Flin and Maran 2015; Flin et al. 2010), yet little effort seems to be taken to neutralize contextual language. Flin et al. (2008) go so far as to state that " $[\ldots]$ it has long been appreciated that the majority of accidents could have been prevented if better non-technical skills had been demonstrated by personnel operating and maintaining the system". In an exemplary fashion, this demonstrates little or no willingness to see team performance as configured in a wider system of constrained adaptive capacities, resource scarcities, and system ambiguities.

Combined with what could almost be understood as an obsession with rating and measuring teamwork in healthcare, one has to ponder whether this trend supports self-fulfilling prophecies or actually contributes to improved patient safety-namely, has the objective in teamwork become to perform satisfactory according to a certain rating system, or to understand teamwork in the hope of ultimately improving patient safety? Fransen et al. (2017) state that "[validated assessment tools] support two purposes; on the one hand they provide objective feedback, on the other they enable reliable comparison between different types of team training" (emphasis added). Dekker (2014, p. 22), on the other hand, argues that " $[\ldots]$ categories into which we put human and social features are infinitely negotiable". While these views certainly constitute two of the possible extremes, what often seems to be overlooked in teamwork research is the need to consciously address the trade-offs required to apply and interpret any taxonomy:

A model that is cumbersome and costly to use will from the very start be at disadvantage, even if it from an academic point of view provides a better explanation. The trick is therefore to find a model that at the same time is so simple that it can be used without engendering problems or requiring too much specialised knowledge, yet powerful enough to go beneath the often deceptive surface descriptions [...] The consequence is rather that we should acknowledge the simplifications that the model brings, and carefully weigh advantages against disadvantages so that a choice of model is made knowingly (Hollnagel and Woods 2006, p. 353)

A predominant focus on individual behaviours, both in training and as the unit of analysis, is oftentimes observed, justified by the fact that teams are comprised of individuals and by their dynamic composition (Flin et al. 2008, pp. 8-9; Østergaard et al. 2011). Combined with the explicit aim of minimizing, trapping and mitigating 'human error', such reductionist team training endeavours in healthcare seem to become increasingly disconnected from relevant developments in safety science of the last 30 years. Although the concept of 'human error' has been questioned, if not abandoned, in contemporary safety thinking (Cook and Nemeth 2010; Woods and Cook 2002; Woods et al. 2010), most of the team training efforts in health care seem to be centred on and build around it. In a sense, the patient safety agenda is being hijacked to serve a more hidden, managerial one: organizational distancing, a defence against entanglement with accidents, and the illusion of control (Cook and Nemeth 2010). Accidents are not attributed to limited resources, an organization "going solid" (Cook and Rasmussen 2005), overloaded wards, a history of underfinancing, or subtle "drift into failure" (Dekker 2011; Hollnagel et al. 2013), but instead to the breakdown of teamwork skills (often at the level of the individual team member). In this way, the notion of teamwork becomes both a promise that managing a complex system is practically possible, and a moral commitment to prevent failure by engaging in the teamwork principles at the 'sharp end' of the system.

\subsection{Contributions from social sciences}

It is worth noting that, in the current discourse on teamwork in healthcare, a substantial body of research is largely being ignored (Finn et al. 2010; Iedema 2009). Contributions from social sciences are rarely mentioned; instead, a more simplistic narrative seems to be accepted that provides more convenient but scientifically impoverished explanations (Vincent 2009).

[C]linicians reduce practical complexity to (technical or moral) abstraction. In doing so, they deny themselves and their colleagues the opportunity to engage with and learn from the actual messiness that characterises their everyday work: divergent understandings, ongoing tensions and pervasive uncertainties. (Iedema 2009)

The relationship between medicine and social sciences is not an easy one, and is beautifully captured by Jackson (1999): "Medicine is the most humanistic of the sciences while also qualifying as the most scientific of the humanities." Vincent (2009) notes that while generally, measurement and data are trusted over opinion in medicine, oftentimes unfamiliarity with qualitative research is mistaken for hostility, impeding open-minded research and a study of wider organizational and cultural factors in the patient safety discourse.

As far as teamwork is concerned, there is a tendency that normative, formal dimensions have been privileged over social and affective ones. Research drawing on both organizational theory and the sociology of healthcare is scarce (Finn 2008; Finn et al. 2010). Its result, however, is a more diversified, critical, and maybe sombre view. In healthcare, 
teamwork as part of the professional identity superimposes the ideal of normative integration over individual interests, thereby overriding identities and aligning them with those of the team (Findlay et al. 1999, as cited by; Finn et al. 2010). What mainstream teamwork literature rarely mentions, or glosses over, is what Finn et al. (2010) call 'micro-political struggles': "Social relations in teamwork, and associated issues of power, conflict and resistance are key, as roles and status need continual negotiation". Ethnographic, descriptive research seems much more sensitive in capturing the intricate web of historically woven relations between different actors, professions and specialties and their ongoing conflicts and struggles than any quantitative approach. Far from the "normative, evangelistic promotion of teamwork within much management and health policy writing" (Finn et al. 2010), it seems almost naïve to ignore the issue of power.

\subsection{Teamwork and power}

"We miss a great deal when we substitute culture for power" (Perrow 1999, p. 380)

While the issue of power with all its organizational facets has been at the heart of Charles Perrow's Normal Accident Theory (1999) for several decades, safety literature has recently started to acknowledge, and even embrace, power on a broader scale (Dekker and Nyce 2014). Obviously, power is an omnipresent force in daily organizational life. Formal authority, distribution of knowledge, control of rewards and resources and coercive power are all important notions that shape and influence organizations (Antonsen 2009).

In the teamwork literature, issues of power implicitly or explicitly permeate all levels of the discourse. When viewed through the power lens, teamwork "[...] reproduces and maintains various forms of occupational inequality, as well as obscur[es] the need for more fundamental change in the work and social context" (Finn et al. 2010). This not only applies to inter- and intraprofessional relations (e.g., nurses vs. doctors, residents vs. attendings), but also on a broader organizational scale ('blunt' vs. 'sharp', management vs. staff) (Finn 2008; Finn et al. 2010; Liberati et al. 2016). This coercive function, however, is oftentimes effectively masked with ideology and language. By framing problems as issues of teamwork, the focus is shifted from other, usually more profound organizational solutions, preventing robust and fundamental change. Within the teams, the egalitarian rhetoric rarely manages to break open encrusted structures and effect sustained change. "Any appeals to egalitarianism these groups make could only be in terms of esteem, equal recognition and the emotional dimensions of work, rather than more fundamental redistribution of material reward and power at the structural level" (Finn et al. 2010).
Dekker and Nyce (2014) introduce a Foucauldian perspective to power in that "[...] power is everywhere we do safety work or safety research-embodied in discourse, knowledge, agency, structure and procedure". One has to be careful, however, not to see this as purely negative, but to acknowledge productive and enabling aspects of power. The potential to shape organizations through empowerment, regardless of its distribution, has to be recognized. ${ }^{2}$

\subsection{The way ahead}

Above, we illustrated from various angles how teamwork is described, understood, enacted and trained in healthcare, both practically and theoretically. Nevertheless, to conceptualize a way ahead for team training in healthcare, we must first try to gain a meta-perspective of the current state. At present, we can only speculate about reasons for why the existing, diverse body of safety knowledge is not readily harnessed in its entirety in medicine. However, based on our own experience, we would suggest far more trivial, if somewhat pragmatic, explanations that are rooted in traditions of academic medical discourse, rather than suspecting wider epistemological schemes. Traditionally, medical research is built on a strong Newtonian understanding of cause and effect. Over centuries, complex issues have been broken down to the smallest accessible denominator, from macroscopic to microscopic to molecular levels, each adding small fragments to an expanding science that has progressively replaced ambiguities and guesswork of the past with new discoveries: from drugs and microorganisms, to signalling pathways, cellular receptors, and, increasingly, our very own DNA as building blocks of life itself. Oftentimes, the most fundamental advances were based on the empirical identification of treatment strategies, and the randomized controlled trial (RCT) has become the "de facto evidential gold standard" (Catchpole and Alfred 2018). While viewing RCTs as the ideal methodology for causal inference, the quest for 'evidence-based medicine' has created an increased dependency on ostensibly objective data, and controversies about where to position medicine in the scientific landscape of 'hard' and 'soft' sciences are ongoing (Deaton and Cartwright 2018; Falzer 2018; Feinstein and Horwitz 1997; Klein et al. 2016). It is also important to consider how this discourse takes place in a society that is increasingly reluctant to accept gaps in knowledge, attribute circumstance to fate or higher religious powers, or accept physicians that simply cannot explain disease, suffering and death. Challenges arise as patient safety issues that were of no concern

\footnotetext{
2 This is a central idea of positivist views on safety, and a role responsibility of leadership in HRO theory (Roberts 1990) or in the design of safety culture (Westrum 2004).
} 
in this data-driven world of medicine only decades ago now increasingly become visible (Kohn et al. 2000; Makary and Daniel 2016) and aspects such as teamwork, hierarchy, or interpersonal relations need to be addressed. This represents one approach to explain the predominant, reductionist understanding of the concept of teamwork in medicine: it is based on how the associated complexities appear manageable amongst an onslaught of new challenges while appealing solutions in the form of normative rating and training instruments are readily available and confirm to the sought-after standards of measurability and comparability. In addition, while expanding the discourse into the social sciences would be the primary responsibility of academic medical institutions, faculty there often not only lacks the time and liberty to do so while juggling the more traditional responsibilities of medical education, resident training, and patient care, but also lacks the necessary education and exposure to scientific fields other than medicine. While it is next to impossible to know how contributions of the social sciences are used by healthcare practitioners trying to be "jacks-of-all-trades", it seems plausible that opening up to a diverse and more complicated narrative is far more difficult than a somewhat protectionist stance, where one stays firmly within its own ontology. In addition, this is likely influenced by whether the social sciences are perceived as mere critics or collaborative contributors (Vincent 2009).

The field would certainly benefit from a more interdisciplinary approach towards the topic that could help combine research traditions from both medicine and the social sciences, while at the same time taking a more expanded, or 'macro' view on how health care is delivered, and how socioeconomic factors that seemingly concern only the much larger system actually 'trickle down' and influence individual healthcare practitioners. In addition, while ongoing efforts of team training should continue, it might be wise to position these in a wider organizational context, rather than applying indiscriminate normative frameworks. Careful evaluation of the composition, scope, and purpose of a given team, combined with individualized content reflective of prevailing culture and organizational needs might yield more sustainable results than current "one-size-fits-all" approaches. Although an intimidating prospect at first, some of these points might be taken care of by emergent phenomena: presently, we can only speculate about the effects that allocation of resources, most notably time, might have on teamwork and team training. It has been repeatedly mentioned how time, or rather the lack thereof, shapes and constraints everyday work in healthcare and reinforces constant fluidity of personnel (Allen 2002; Lewin and Reeves 2011). Ad hoc, informal activity, meetings, and communication, sometimes called "backstage" activity (Lewin and Reeves 2011), are oftentimes much more important in organizing daily work than planned, visible structures; however, these 'hidden' mechanisms are rarely considered in current team training concepts. While indiscriminate 'CRM'-type training of normative behaviour might create the outward appearance of interprofessional collaboration, its effects on everyday work will likely remain superficial at best if not properly complemented by organizational reflection and mindfulness towards social processes and dynamics at the workplace. Organizational efforts concentrated on teamwork training underscore not only the prevailing desire to believe in a reductionist model, but also the illusion that local control is possible regardless of more macro system features and behaviour. It reinforces the concept of institutional safety as the product of individual virtues despite organizational hysteresis, an approach that is consistent with the technical and pragmatic, problem-solving origins of safety science (Dekker and Nyce 2014). However, this operationally convenient but conceptually simplistic approach is bound to continue the responsibilization of local, frontline staff in yet another exercise of power. The way ahead might lie in efforts to increase awareness and strategically change power dynamics; this would represent a far more profound rethinking of organizational processes, but will require the allocation of resources and a willingness to fundamentally remodel parts of systems rather than mere teamwork strategies.

\section{Conclusion}

Teamwork in healthcare remains a topic of great interest for both practitioners and researchers. It appears that currently, medicine has settled for a reductionist and moral approach towards teamwork to manage the associated complexities, thereby accepting a simplistic but intellectually impoverished and ethically questionable understanding of the concept. This is not only confusing for practitioners, but in disregard of their needs and in stark contrast to the way their professional identities are otherwise constructed and understood. Compared to the sophisticated professional standards set for practitioners, one has to challenge what it takes to teach, train, and evaluate teamwork in healthcare. It appears that healthcare would be well served to scrutinize questions of legislation, content, and accountability in team training. In addition, despite the need for measurements and evaluation, the continuous integration of social and cultural aspects in teamwork research will most likely enrich the current discourse for a more humanistic and complete understanding of what happens in healthcare teams. Recognizing power dynamics at the workplace in an effort to understand team processes and guide the serious allocation of resources will certainly address current challenges faced by frontline medical staff more thoroughly than the application of normative frameworks. Before rating their 'sharpness', we should harness their narratives and listen to their current needs. 
Acknowledgements Dag Erik Lutnæs would like to thank the Laerdal Foundation for financial support to attend the MSc program on Human Factors and Systems Safety at Lund University.

\section{Compliance with ethical standards}

Conflict of interest This review is in partial fulfilment of the requirements for the MSc in Human Factors and Systems Safety at Lund University for both $\mathrm{CN}$ and $\mathrm{DEL}$, who are students in the program.

OpenAccess This article is distributed under the terms of the Creative Commons Attribution 4.0 International License (http://creativeco mmons.org/licenses/by/4.0/), which permits unrestricted use, distribution, and reproduction in any medium, provided you give appropriate credit to the original author(s) and the source, provide a link to the Creative Commons license, and indicate if changes were made.

\section{References}

Allard J, Bleakley A, Hobbs A, Coombes L (2011) Pre-surgery briefings and safety climate in the operating theatre. BMJ Qual Saf 20(8):711-717. https://doi.org/10.1136/bmjqs.2009.032672

Allen D (2002) Time and space on the hospital ward: shaping the scope of nursing practice Nursing and the Division of Labour in Healthcare. Springer, Berlin, pp 23-51

Antonsen S (2009) Safety culture and the issue of power. Saf Sci 47(2):183-191

Arriaga AF, Bader AM, Wong JM, Lipsitz SR, Berry WR, Ziewacz JE, Gawande AA (2013) Simulation-based trial of surgical-crisis checklists. N Engl J Med 368(3):246-253. https://doi.org/10.1056/ NEJMsa1204720

Baumeister RF, Leary MR (1997) Writing narrative literature reviews. Rev Gen Psychol 1(3):311

Braithwaite J, Clay-Williams R, Nugus P, Plumb J (2013) Health care as a complex adaptive system. In: Hollnagel E, Braithwaite J, Wears RL (eds) Resilient health care. CRC Press, Boca Raton

Burke CS, Volpe C, Cannon-Bowers JA, Salas E (1993) So what is teamwork anyway? A synthesis of the team process literature. In: Paper presented at the 39th annual meeting of the Southeastern Psychological Association, Atlanta, GA

Cannon-Bowers JA, Tannenbaum SI, Salas E, Volpe CE (1995) Defining competencies and establishing team training requirements. In: Guzzo RA, Salas E (eds) Team effectiveness and decision making in organizations, 1st edn. Jossey-Bass, San Francisco, pp 333-380

Catchpole K, Alfred M (2018) Industrial conceptualization of health care versus the naturalistic decision-making paradigm: work as imagined versus work as done. J Cogn Eng Decis Mak 12(3):222226. https://doi.org/10.1177/1555343418774661

Catchpole KR, Giddings AE, Wilkinson M, Hirst G, Dale T, de Leval MR (2007) Improving patient safety by identifying latent failures in successful operations. Surgery 142(1):102-110. https://doi. org/10.1016/j.surg.2007.01.033

Conklin T (2018) PAPod 167-what is next for safety II-Erik Hollnagel [Audio Podcast]. https://preaccidentpodcast.podbe an.com/?s=167. Accessed 31 Mar 2018

Cook RI, Nemeth CP (2010) Those found responsible have been sacked": some observations on the usefulness of error. Cogn Technol Work 12(2):87-93

Cook R, Rasmussen J (2005) "Going solid'": a model of system dynamics and consequences for patient safety. Qual Saf Health Care 14(2):130-134
Deaton A, Cartwright N (2018) Understanding and misunderstanding randomized controlled trials. Soc Sci Med 210:2-21. https://doi. org/10.1016/j.socscimed.2017.12.005

Dekker S (2011) Drift into failure: from hunting broken components to understanding complex systems. Ashgate, Farnham

Dekker S (2014) Field guide to understanding 'human error', 3rd edn. Ashgate, Farnham

Dekker SWA, Nyce JM (2014) There is safety in power, or power in safety. Saf Sci 67:44-49. https://doi.org/10.1016/j. ssci.2013.10.013

Dekker S, Cilliers P, Hofmeyr J-H (2011) The complexity of failure: implications of complexity theory for safety investigations. Saf Sci 49(6):939-945. https://doi.org/10.1016/j.ssci.2011.01.008

Falzer PR (2018) Naturalistic decision making and the practice of health care. J Cogn Eng Decis Mak 12(3):178-193. https://doi. org/10.1177/1555343418773915

Feinstein AR, Horwitz RI (1997) Problems in the "evidence" of "evidence-based medicine". Am J Med 103(6):529-535

Findlay P, McKinlay A, Marks A, Thompson P (1999) Flexible when it suits them: the use and abuse of teamwork skills. In: Proctor S, Mueller F (eds) Teamworking. Macmillan Publishers, London, pp 222-243

Finn R (2008) The language of teamwork: reproducing professional divisions in the operating theatre. Hum Relat 61(1):103-130. https://doi.org/10.1177/0018726707085947

Finn R, Learmonth M, Reedy P (2010) Some unintended effects of teamwork in healthcare. Soc Sci Med 70(8):1148-1154. https ://doi.org/10.1016/j.socscimed.2009.12.025

Flin R, Maran N (2015) Basic concepts for crew resource management and non-technical skills. Best Pract Res Clin Anaesthesiol 29(1):27-39. https://doi.org/10.1016/j.bpa.2015.02.002

Flin RH, O'Connor P, Crichton M (2008) Safety at the sharp end: a guide to non-technical skills. Ashgate, Aldershot

Flin R, Winter J, Cakil Sarac MR (2009) Human factors in patient safety: review of topics and tools. (WHO/IER/PSP/2009.05). World Health Organization, Geneva

Flin R, Patey R, Glavin R, Maran N (2010) Anaesthetists' non-technical skills. Br J Anaesth 105(1):38-44. https://doi.org/10.1093/ bja/aeq134

Fransen AF, de Boer L, Kienhorst D, Truijens SE, van Runnard Heimel PJ, Oei SG (2017) Assessing teamwork performance in obstetrics: a systematic search and review of validated tools. Eur J Obstet Gynecol Reprod Biol 216:184-191

Gaba DM (1989) Human error in anesthetic mishaps. Int Anesthesiol Clin 27(3): 137-147

Haynes AB, Weiser TG, Berry WR, Lipsitz SR, Breizat AH, Dellinger EP (2009) Safe Surgery Saves Lives Study. A surgical safety checklist to reduce morbidity and mortality in a global population. N Engl J Med 360(5):491-499. https://doi. org/10.1056/NEJMsa0810119 G.

Helmreich RL, Merritt AC, Wilhelm JA (1999) The evolution of Crew Resource Management training in commercial aviation. Int J Aviat Psychol 9(1):19-32. https://doi.org/10.1207/s1532 7108ijap0901_2

Hollnagel E (2014) Safety-I and safety-II: the past and future of safety management. Ashgate, Farnham

Hollnagel E, Woods D (2006) Epilogue: resilience engineering precept. In: Hollnagel E, Woods D, Leveson N (eds) Resilience engineering: concepts and precepts. Ashgate, Farnham, UK, pp 347-358

Hollnagel E, Pariès J, Woods DD, Wreathall J (2011) Resilience engineering in practice: a guidebook. Ashgate, Farnham

Hollnagel E, Braithwaite J, Wears RL (2013) Resilient health care. CRC Press, Boca Raton

Howard SK, Gaba DM, Fish KJ, Yang G, Sarnquist FH (1992) Anesthesia crisis resource management training: teaching 
anesthesiologists to handle critical incidents. Aviat Space Environ Med 63(9):763-770

Iedema R (2009) New approaches to researching patient safety. Soc Sci Med 69(12):1701-1704. https://doi.org/10.1016/j.socsc imed.2009.09.050

Ilgen DR (1999) Teams embedded in organizations: some implications. Am Psychol 54(2):129

Jackson S (1999) The role of stress in anaesthetists' health and wellbeing. Acta Anaesthesiol Scand 43(6):583-602

Jepsen RM, Østergaard D, Dieckmann P (2015) Development of instruments for assessment of individuals' and teams' non-technical skills in healthcare: a critical review. Cogn Technol Work 17(1):63-77

Klampfer B, Flin R, Helmreich R, Häusler R, Sexton B, Fletcher G, Dieckmann $P$ (2001) Enhancing performance in high risk environments: recommendations for the use of behavioural markers. Gottlieb Daimler und Karl Benz Stiftung, Berlin

Klein DE, Woods DD, Klein G, Perry SJ (2016) Can we trust best practices? Six cognitive challenges of evidence-based approaches. J Cogn Eng Decis Mak 10(3):244-254

Kohn LT, Corrigan J, Donaldson MS (2000) To err is human: building a safer health system. National Academy Press, Washington, DC

Lemieux-Charles L, McGuire WL (2006) What do we know about health care team effectiveness? A review of the literature. Med Care Res Rev 63(3):263-300

Levitt P (2014) Challenging the systems approach: why adverse event rates are not improving. BMJ Qual Saf 23(12):1051-1052. https ://doi.org/10.1136/bmjqs-2014-003569

Lewin S, Reeves S (2011) Enacting 'team' and 'teamwork': using Goffman's theory of impression management to illuminate interprofessional practice on hospital wards. Soc Sci Med 72(10):1595-1602. https://doi.org/10.1016/j.socscimed.2011.03.037

Liberati EG, Gorli M, Scaratti G (2016) Invisible walls within multidisciplinary teams: disciplinary boundaries and their effects on integrated care. Soc Sci Med 150:31-39. https://doi.org/10.1016/j. socscimed.2015.12.002

Lorello GR, Cook DA, Johnson RL, Brydges R (2014) Simulationbased training in anaesthesiology: a systematic review and metaanalysis. Br J Anaesth 112(2):231-245. https://doi.org/10.1093/ bja/aet414

Makary MA, Daniel M (2016) Medical error - the third leading cause of death in the US. BMJ 353:i2139. https://doi.org/10.1136/bmj. i2 2139

Manser T (2009) Teamwork and patient safety in dynamic domains of healthcare: a review of the literature. Acta Anaesthesiol Scand 53(2):143-151. https://doi.org/10.1111/j.1399-6576.2008.01717.x

Manser T, Howard SK, Gaba DM (2008) Adaptive coordination in cardiac anaesthesia: a study of situational changes in coordination patterns using a new observation system. Ergonomics 51(8):11531178. https://doi.org/10.1080/00140130801961919

McGrath JE (1964) Social psychology: a brief introduction. Holt, Rinehart and Winston, Canada

Morey JC, Simon R, Jay GD, Wears RL, Salisbury M, Dukes KA, Berns SD (2002) Error reduction and performance improvement in the emergency department through formal teamwork training: evaluation results of the MedTeams project. Health Serv Res 37(6): 1553-1581

Neuhaus C, Hofer S, Hofmann G, Wachter C, Weigand MA, Lichtenstern C (2016) Perioperative safety: learning, not taking, from aviation. Anesth Analg 122(6):2059-2063. https://doi.org/10.1213/ ANE.0000000000001315

Neuhaus C, Spies A, Wilk H, Weigand MA, Lichtenstern C (2017) "Attention Everyone, Time Out!": safety attitudes and checklist practices in anesthesiology in Germany. A cross-sectional study. J Patient Saf. https://doi.org/10.1097/pts.0000000000000386 (June 1, 2017-Published ahead of print)
Ornato JP, Peberdy MA (2014) Applying lessons from commercial aviation safety and operations to resuscitation. Resuscitation 85(2):173-176. https://doi.org/10.1016/j.resuscitat ion.2013.10.029

Østergaard D, Dieckmann P, Lippert A (2011) Simulation and CRM. Best Pract Res Clin Anaesthesiol 25(2):239-249

Paré G, Trudel M-C, Jaana M, Kitsiou S (2015) Synthesizing information systems knowledge: a typology of literature reviews. Inf Manag 52(2):183-199. https://doi.org/10.1016/j.im.2014.08.008

Paris CR, Salas E, Cannon-Bowers JA (2000) Teamwork in multiperson systems: a review and analysis. Ergonomics 43(8):10521075. https://doi.org/10.1080/00140130050084879

Perrow C (1999) Normal accidents: living with high risk technologies. Princeton University Press, Princeton

Rasmussen J (1997) Risk management in a dynamic society: a modelling problem. Saf Sci 27(2):183-213

Rasmussen J, Nixon P, Warner F (1990) Human error and the problem of causality in analysis of accidents (and discussion). Philos Trans R Soc Lond B Biol Sci 327(1241):449-462

Reznek M, Smith-Coggins R, Howard S, Kiran K, Harter P, Sowb Y, Krummel T (2003) Emergency medicine crisis resource management (EMCRM): pilot study of a simulation-based crisis management course for emergency medicine. Acad Emerg Med 10(4):386-389

Roberts KH (1990) Some characteristics of one type of high reliability organization. Organ Sci 1(2):160-176

Roberts KH, Madsen P, Desai V, Van Stralen D (2005) A case of the birth and death of a high reliability healthcare organisation. Qual Saf Health Care 14(3):216-220. https://doi.org/10.1136/ qshc.2003.009589

Rochlin GI (1999) Safe operation as a social construct. Ergonomics 42(11):1549-1560. https://doi.org/10.1080/001401399184884

Rochlin GI, La Porte TR, Roberts KH (1987) The self-designing high-reliability organization: aircraft carrier flight operations at sea. Nav War Coll Rev 40:76-90

Russ S, Rout S, Sevdalis N, Moorthy K, Darzi A, Vincent C (2013) Do safety checklists improve teamwork and communication in the operating room? A systematic review. Ann Surg 258(6):856871. https://doi.org/10.1097/sla.0000000000000206

Rydenfalt C, Johansson G, Odenrick P, Akerman K, Larsson PA (2013) Compliance with the WHO Surgical Safety Checklist: deviations and possible improvements. Int J Qual Health Care 25(2):182-187. https://doi.org/10.1093/intqhe/mzt004

Salas E, Burke CS, Cannon-Bowers JA (2000) Teamwork: emerging principles. Int J Manag Rev 2(4):339-356

Salas E, Wilson KA, Burke CS, Wightman DC (2006) Does crew resource management training work? An update, an extension, and some critical needs. Hum Factors 48(2):392-412

Salas E, Cooke NJ, Rosen MA (2008) On teams, teamwork, and team performance: discoveries and developments. Hum Factors 50(3):540-547

Schmutz J, Manser T (2013) Do team processes really have an effect on clinical performance? A systematic literature review. $\mathrm{Br} \mathbf{J}$ Anaesth 110(4):529-544. https://doi.org/10.1093/bja/aes513

Schulman PR (2004) General attributes of safe organisations. Qual Saf Health Care 13(SUPPL. 2):ii39-ii44. https://doi. org/10.1136/qshc.2003.009613

Sundstrom ED (1999) Supporting work team effectiveness: best management practices for fostering high performance. Jossey-Bass Publishers, San Francisco

Vincent C (2009) Social scientists and patient safety: critics or contributors? Soc Sci Med 69(12):1777-1779. https://doi. org/10.1016/j.socscimed.2009.09.046

Vincent C, Amalberti R (2016) Safer healthcare. Springer International Publishing, Heidelberg 
Weaver SJ, Lyons R, DiazGranados D, Rosen MA, Salas E, Oglesby J, King HB (2010) The anatomy of health care team training and the state of practice: a critical review. Acad Med 85(11):17461760. https://doi.org/10.1097/ACM.0b013e3181f2e907

Weber DE, Dekker SW (2017) Assessing the sharp end: reflections on pilot performance assessment in the light of safety differently. Theor Issues Ergon Sci 18(1):59-78

Westrum R (2004) A typology of organisational cultures. Qual Saf Health Care 13(suppl 2):ii22-ii27

Woods DD (2015) Four concepts for resilience and the implications for the future of resilience engineering. Reliab Eng Syst Saf 141(Supplement C):5-9. https://doi.org/10.1016/j. ress.2015.03.018

Woods DD, Cook RI (2002) Nine steps to move forward from error. Cogn Technol Work 4(2):137-144. https://doi.org/10.1007/s1011 10200012
Woods DD, Dekker S, Cook R, Johannesen L, Sarter N (2010) Behind human error, 2nd edn. Ashgate, Farnham

Yule S, Flin R, Paterson-Brown S, Maran N (2006) Non-technical skills for surgeons in the operating room: a review of the literature. Surgery 139(2):140-149

Publisher's Note Springer Nature remains neutral with regard to jurisdictional claims in published maps and institutional affiliations. 